\title{
Um novo paradigma em Gestão Pública
}

Bernardo Kilksberg

Diretor do Programa Regional das Nações Unidas para o

Desenvolvimento e Capacitação de Gerência no Setor Público.

Tradução: Jaime Valderrama Herrera

\section{1 - O GRANDE DEBATE}

As principais forças politicas e sociais da América Latina passaram a formular, de modo cada vez mais contundente e legitimado, uma série de questões sobre o Estado. É lógico que essas questōes assumissem formas mais determinadas. Nossos povos estão se debatendo numa encruzilhada histórica. De um lado, avança o grande projeto de construção de democracias estáveis, projeto esse de longo prazo e repleto de promessas. Do outro, a partir dos anos 80 , a presença da crise econômica mais aguda pela qual a região já atravessou neste século. Amplos setores de estrutura social percebem que o Estado terá um papel estratégico na solução desse dilema histórico. Em conseqüência, propõem, de modo quotidiano, questões totalmente substantivas.

Será possivel passar a um
estágio que possa dar
respostas mais efetivas que os
fracassos que abarrotaram o
cenário das reformas do
Estado

Como tornar eficiente o Estado atual que apresenta níveis limitados de produtividade em extensas áreas? Como abrir esse Estado e transformálo num Estado de conformidade com as bases do projeto democrático, num estado próximo dos cidadãos, transparente e disposto à comunicação, ao diálogo e controle social? Como conseguir formar uma geração de gerentes no setor público capazes de atuar com eficiência técnica e critério na- cional na tomada de decisões básicas? As perguntas continuam e culminam numa questão central: Será este Estado viável? Porque diversas vezes fracassaram as promessas, os planos mais ambiciosos, os sucessivos projetos de "reforma administrativa"?

Que possibilidade existe em termos de ciência e tecnologia da gestão, de dar respostas razoáveis a essas perguntas? Bernard Schaffer, que dirigiu o Instituto de Desenvolvimento Econômico da Universidade de Sussex, assinala, em relação ao "estado da arte" na matéria, que "a administração pública, como é convencionalmente entendida e pensada, aparece como uma matéria inchada, autoimportante, auto-indulgente, bastante periférica em relação aos fatos do comportamento político e administrativo e às forças que modelam a mudança social",(1) A sua caracterização incisiva descreve o que poderíamos chamar de paradigma tradicional em matéria de reflexão e ação no que se refere à administração pública. Será possivel passar desse paradigma tradicional a um outro estágio distinto que possa dar algumas respostas mais efetivas do que os fracassos que abarrotam o cenário das reformas do Estado? Como fazer isso? Esse é o tema central no qual queremos nos concentrar. Achamos que existem tendências significativas de mudança nesse aspecto da realidade regional, com o apoio e pontos de referência a nivel internacional, que representa, provavelmente, o início de uma possibilidade séria para se chegar a respostas efetivas. Propomo-nos a explorar esses esforços de revisão conceitual e técnica. Trabalharemos três momentos sucessivos de análise.

Em primeiro lugar, existem questionamentos profundos em desenvol- vimento ativo, que chamaríamos de "gargalos conceituais", em matéria de trabalho na administração pública, existem, também, certos estilos e modelos de pensar todo o problema que levam, necessariamente, a caminhos sem saída. Muitos desses enfoques são, atualmente, impugnados por diferentes perspectivas e abordagens. Num primeiro momento vamos enfatizar alguns desses questionamentos.

Em segundo lugar, passaremos dos esforços críticos ao trabalho de estruturação de propostas técnicas alternativas, também em andamento.

Formularemos alguns propósitos em relação a algumas das linhas em que se está desenvolvendo o início de uma nova fronteira tecnológica, em matéria de análise e gestão do aparato público.

Num terceiro momento, examinaremos como, utilizando alguns dos insumos intelectuais e práticos fornecidos pelos dois processos anteriores e em. estreita interação, se está produzindo, na América Latina, um novo ciclo de movimento de reforma do Estado que pode denominar-se de "reforma da reforma".

Vamos desenvolver esses apontamentos num nivel introdutório, tratando de fornecer propósitos esquemáticos que possam dar uma idéia das linhas do "grande debate" em curso. Por outro lado, trabalharemos apenas a nível de tendências gerais, sem entrar nos modos especificos de apresentação diferenciada das diversas realidades.

\section{II - QUESTIONANDO OS "GAR- GALOS CONCEITUAIS"}

O modo de pensar o problema da "Administração Pública Convencional”, apresenta deficiências múltiplas 


\section{ESTUDOS}

que obstruem o avanço na produção de acontecimentos e geração de mudanças efetivas no aparato público. Vejamos algumas, obviamente não taxativas.

\section{A - AS INSUFICIÊNCIAS DO "DISCURSO"}

Em primeiro lugar, é possível produzir um sério questionamento sobre as insuficiências metodológicas e epistemrológicas, características do tratamento usual de todo o tema, importante a nivel científico-básico e em termos de opinião pública quotidiana. O discurso relativo ao Estado tnde a praticar, na América Latina, entre outros, os seguintes "estilos".

\section{Na América Latina, o discurso relativo ao Estado tende a ser genérico $e$ redunda em conclusões do tipo círculo vicioso e infecundas}

Primeiramente, é um discurso alheio à história. Parece que o tema da administração pública, sua ineficiência, o crescimento do setor de c'mpresas públicas, etc., é um tema que se poderia analisar à margem do processo histórico-social geral, quando ao contrário somente pode ser entendido seriamente ao instalat-se dentro do referido processo. Nenhum dos processos típicos do aparato público atual surgiu do nada, cles surgiram num decurso, cuja lógica deve ser pesquisada para entender as forças subjacentes e extrair conclusōes sobre a possibilidade de sua influência no futuro. O "discurso" tende a enfocar, exclusivamente, a conjuntura imediata, sem entrar na análise histórica. É ai entâo que podem aparecer "patologias", o que historicamente são respostas funcionais, e os problemas estruturais reais, acumulados através de processos de longo prazo, podem também ficar evidenciados.
Em segundo lugar, o discurso normalmente não é desagregado. Os rótulos são de caráter absolutamente global. Assim, fala-se de administração pública "metafisicamente". Em qualquer Estado latino-americano, coexistem diversos tipos de aparatos públicos: o governo central, cujo tipo de administração é de ordem usualmente tradicional; o setor de empresas públicas que é outra "administração pública mais moderna"; as entidades autônomas; as burocracias regionais e municipais que são ainda outros tipos diferentes de administração pública. Que valor prático existe pois em se falar de administração pública de forma genérica? A administração pública global é heterogênea e altamente diferenciada. O discurso nào desagregado leva a uma destacada pobreza da análise e das conclusões. Por exemplo, algumas pesquisas significativas realizadas, nos últimos anos, na Europa, sobre o fenômeno da corrupção administrativa, ilustram o que é basear um discurso em categorias absolutas ou $\mathrm{cm}$ abordagens desagregadas. O tratamento do tema, na América Latina, é genérico e redunda em conclusòes do tipo "círculo vicioso" e infecundas. Na Europa, apos ter-se tratado problema com rigor e produzir estatisticas, procurousc estabelecer as relações entre os fenòmenos de corrupçào e diversas variaveis para se chegar a tipologias. Assim. cm alguns casos, assinalou-se quic, provavelmente, a "classe" de corrupcion yue ocorre no processo de formulaçào da política pública é muito mais importante do que aquela mais visivel e produzida no processo de implantação da mesma. São duas formas diferentes de corrupção, cujos efeitos no funcionamento global são variados.

Além de o discurso estar fora do contexto histórico, não ser desagregado, também nào pode ser comparado. Um critério metodológico básico, na área do social, é tratar de verificar as caracteristicas que os mesmos tipos de processo adquirem, vis-à-vis a outras realidades regionais e internacionais, enriquecendo assim possibilidades de análise. Esse critério central de trabalho é pouco aplicado no modo como o discurso pensa a administração pública. Não se traçam paralelos com processos similares de outras áreas em desenvolvimento ou com o próprio mundo desenvolvido.

\section{B - AS DIFICULDADES PRE- SENTES NOS NÍVEIS DF ANÁLISE}

Uma séria dificuldade surge quando se trata de avançar na matéria, é a dificuldade que surge nos niveis de análise nos quais se realiza o trabalho na região. De um lado, existe uma perspectiva "macro" que trata o tema da administração pública a nivel de "grande teoria", examinando-o, como uma espécie de subtema inferior do grande tema da reflexão, em relação ao desenvolvimento econômicosocial, à dependência, à teoria política do Estado latino-americano, etc... Esse grande tema é válido e fundamental, mas não capta em si a especificidade do aparato público, processo histórico particular dentro do processo histórico global. A partir, unicamente, da grande teoria, é impossível compreender o aparato porque a sua complexidade requer uma teoria particular ligada à grande teoria, e que tenha os seus próprios enfoques metodológicos. Do outro lado, prevalece um enfoque "micro" exclusivamente concentrado em aspectos pontuais do tema como procedimentos, métodos, organização formal, válidos em si, mas que de modo algum dão conta da complexidade do comportamento burocrático.

\section{$O$ direito administrativo}

ensina ao cidadão como defender-se do poder público, mas não diz como ele deve

$$
\text { agir }
$$

Tanto o enfoque macro quanto o micro costumam ter acentuadas ca. racteristicas juridicas. A grande teoria, às vezes, se apresenta ao aparato público como uma grande teoria do direito constitucional ou administrativo, e o enfoque micro orienta-se, normalmente para a formulação ju rídica, como o seu desiderato. Um destacado catedrático do direito ad 


\section{ESTUDOS}

ministrativo espanhol, ALEJANDRO NIETO, diz a respeito: "A perspectiva jurídica, apenas tocando de leve a superfície das coisas, adquire, inevitavelmente, a sensação - aliás muito justa - de que não tem acesso ao verdadeiro núcleo dos problemas. $\mathrm{O}$ direito administrativo ensina, efetivamente, como o cidadão pode defender-se das agressões do poder público, mas não diz nada ou quase nada sobre como a administração deve agir para ter um minimo de eficiência e responder eficazmente às exigências sociais. Para o direito administrativo, é um mero aparato formal, apenas atento à legalidade de suas atividades, e não ao conteúdo das mesmas e muito menos em relação à sua realidade".'(2)

Tanto o macro quanto o micro e suas perspectivas jurídicas, margeiam a dinâmica central própria do aparato público, com sua enorme densidade, e ao fugir dessa perspectiva, a possibilidade de entender essa dinâmica e de poder influenciá-la se restringe seriamente.

\section{C - O CASO DO TEMA DO TA- MANHO DO ESTADO}

Alguns temas são tratados com acentuada superficialidade por serem o resultado de outros aspectos das características do debate. Um caso típico é o tema do tamanho do Estado, que quase substitui o tema da eficiência da administração pública. Poderia parecer que o problema seria exclusivamente de dimensão. Tende-se a criar a imagem mistica de que se reduzirmos o tamanho conquistar-se-á ipso facto a eficiência. O tema assume outro aspecto distinto quando se agregam elementos de análise histórica e comparada. $\mathrm{O}$ exame histórico dá conta das forças estruturais que tendem a uma ampliação do tamanho e do seu caráter altamente difundido. Por outro lado, a nivel de comparação, o que quer dizer Estado grande, médio ou pequeno? De acordo com o relatório do Banco Mundial sobre o setor público, em 1983, na primeira parte do século, a relação entre dispêndio público e o PIB era, nos países desenvolvidos, de $10 \%$. Hoje en dia, nesses mesmos países, a relação é de $40 \%$ e são bem maiores do que o tamanho do Estado na grande maioria dos paises da América Latina. Essa mesma relação é de $45 \%$ na Alemanha Ocidental.

A medida que o debate nâo é histórico, nem comparativo, vai-se de encontro a uma lógica falsa

Existem diferenças fundamentais no que se refere ao tipo de Estado, o seu papel, etc. mas a comparação evidencia a pouca produtividade que existe no tratamento do tema, exclusivamente sob o ponto de vista do "reducionismo" de tamanho.

Um trabalho recente de pesquisa, publicado no American Economic Review, e realizado pelo Professor RATI RAM, da Universidade de Illinois, arrola uma evidência empírica significativa em relação ao assunto. A pesquisa estuda 115 paises, durante 20 anos $(1960 / 1980)$, e mede as correlações estatísticas entre o tamanho do Estado e outros aspectos. As conclusões do trabalho são as seguintes: a) ao crescer o tamanho do Estado, o PIB cresce; b) ao crescer o tamanho cresce também o produto bruto nào governamental (economia privada) e c) o crescimento de ambos os fatores foi maior nos paises onde o PIB era menor no início.(3) O tema deveria ser rediscutivo e ao fazer isso, provavelmente, a coisa muda, pois passa do tema do tamanho ao tema do papel histórico do Estado e de sua capacidade de gestão para poder desempenhar esse papel. A medida que o debate não é histórico, nem comparativo, vai-se de encontro a uma lógica falsa.

\section{D - O "REDUCIONISMO" FOR- MALISTA}

Um questionamento, já em etapa avançada, se refere ao processo de destruição definitiva, dentro da teoria gerencial moderna, do "reducionismo formalista" de alta incidência nos processos de reforma administrativa na América Latina. ${ }^{(4)}$ Toda essa concepção da organização como conjunto de relações funcionais e arranjos formais, a ser otimizada através de organogramas, procedimentos, manuais de normas, etc., resulta numa frente unilateral e estreita diante das inúmeras pesquisas que realçam a multiplicidade de variáveis operativas. Uma pesquisa recente de Colebatch e Degeling sobre um municipio inglês concluiu: "para os participantes, o governo municipal não é um organismo simples mas sim um mundo de atores diferenciados com interesses isolados e às vezes em conflito,

Essa concepção da
organização resulta numa
frente unilateral e estreita,
diante da multiplicidade de
variáveis operativas

buscando os recursos necessários para realizá-los. O processo em que estão envolvidos se caracteriza mais pelo conflito, descontinuidade e ambigüidade do que por um movimento claro em direção a metas acordadas. $\mathrm{O}$ fluxo da ação não é hierárquico, as iniciativas podem vir de baixo como podem vir de cima da organização ou de fora, como de dentro; freqüentemente é até ilusório dizer que os conselheiros tomam a decisão acerca da ação a ser empreendida. Como os interesses estão fragmentados, os participantes estão constantemente envolvidos na busca de coalizôes para apoiar suas atividades".(5) Frente a esse diagnóstico da realidade de um governo municipal concreto de uma cidade inglesa, torna-se obsoleta e limitada a análise formal da organizado, com a sua visão, a priori, da mesma, representando uma série de estruturas hierárquicas que funcionam de cima para baixo, e comunicaçōes de baixo para cima, etc... A realidade inclui esses elementos formais, porém é bem mais ampla e se caracteriza pelo jogo multifacetado e contraditório já descrito. A aplicação da visão for- 


\section{ESTUDOS}

malista, como método básico de percepção das organizações, constitui-se num obstáculo sério para se poder pensar e agir eficientemente em relação às referidas organizações.

\section{E - A ASSIMILAÇÃO MECÂNI- CA DA GESTÂO PÚBLICA E DA GESTÃO PRIVADA}

O discurso não desagregado e alheio ao contexto histórico, tende a tratar indiferentemente o problema básico da administração do setor público e do setor privado, assimilando-os.

Daí a necessidade de repetir, no setor público, as categorias, objetivos e técnicas da gestão privada assim como sugerir a formação dos gerentes públicos nas escolas de "Business Administration" e na versão extrema, a gestão direta de setores públicos por * empresários privados bem-sucedidos.

As evidências nas pesquisas vão em outra direção, diferente da assimilação mecânica. Um simpósio americano sobre produtividade no setor público, organizado pela Universidade do Arizona, conclui que nào se pode falar de produtividade no setor público, nem assimilando-à à do setor privado, nem tratando igualmente ass diferentes e heterogêneos sctores que integram o mesmo setor público. Desstaca ainda que no aparato publico. deve-se perguntar: produtividade, para quem e para que propositos?(k) A produtividade de um Ministério de Relações Exteriores, deve ser medida com categorias diferentes da produtividade de uma empresa de servicos e ambas diferem da produtividade de um municipio.

Essas diferenças levam a profundas dessemelhanças nos "enquadramentos gerenciais" e nas técnicas aplicáveis.

Um trabalho de campo, recente, tecnicamente orientado pela Universidade de Boston, realizado num pais latino-americano, estabeleceu crité- rios que permitiram medir a produtividade das empresas públicas, no intuito de instalar um sistema de controle da gestão. O trabalho descartou a noção de utilidade privada como possibilidade de medir a produtividade das empresas públicas, pois encontrou problemas múltiplos que a tornaram um indicador inadequado. Entre esses problemas aparecem os de definição contábil, por exemplo os preços, os de atribuição, conceptuais e qualitativos que não medem cobertura ou qualidade de serviços, etc. Em seu lugar propõe, com fundamentos significativos, a noção de utilidade pública que se mediria através de um sistema de preços sombra e de indicadores de desempenho, que traria toda ordem de implicações em termos de gerência. Ambas as pesquisas e muitas outras semelhantes indicam o "simplismo" da assimilação mecânica. Os principais centros de formação gerencial pública têm, entre os seus pontos de partida, a superação desse simplismo. A escola de Governo, JOHN F. KENNEDY, da Universidade de Harvard assim diz: "Em contraste com a educação para os negócios, o treinamento para a vida pública requer uma profunda compreensão do contexto politico e constitucional da gestäo governamental, onde a autoridade o poder se encontram amplamente difundidos. Enquanto tanto a cmpresa privada quanto o governo requerem uma gerência eficiente, os instrumentos manejados por um executivo de negócios são freqüentemente as próprias restrições com que - gerente público deve trabalhar".(7) O Instituto de Administração Pública de Paris destaca que a base da nocào de gerência pública é "o reconhecimento da especificidade das organizaçōes públicas".( $(8)$

$$
\begin{gathered}
\text { Em contraste com a } \\
\text { educação para negócios, o } \\
\text { treinamento para a vida } \\
\text { pública requer uma profunda } \\
\text { compreensão do contexto } \\
\text { político e constitucional da } \\
\text { gestão governamental }
\end{gathered}
$$

\section{F - ERROS NA PERCEPÇÃO DA EXCELÊNCIA GERENCIAL}

Na América Latina, tradicionalmente, vinculou-se a excelência gerencial ao clássico POSDCORB DE GURICK. O gerente "ideal" seria aquele que manejasse, com toda a eficiência, as funções de planejamento, organização, administração de pessoal, direção, coordenação, saber relatar e orçamentação, todas elas sob o ponto de vista de uma perspectiva formalista. Seria, basicamente, o gerente capaz de manejar a organização formal. A teoria gerencial moderna se encontra numa etapa fatalmente diferente. Pesquisas, como as de HENRY MINTZBERG, do Canadá, que enfatizaram sistematicamente a atividade real dos gerentes bem-sucedidos, chegam à conclusão de que eles têm como grandes funções: a relação interpessoal, o manejo da informação e a tomada de decisão que envolve componentes importantes de negociação institucional e da qual o POSDCORB é um aspecto. ${ }^{(9)}$ Pesquisas, como a de JONH KOTTER, da Universidade de Harvard, vão mais longe, concluindo, a partir de uma amostra de gerentes de excelência nos E.U.A., que o básico dessa suficiência é a capacidade para "armar a agenda das decisões", discernir quais são os temas estratégicos, e a capacidade de construir "a rede de contatos" internos e externos que torne viável a implementação das decisōes. Para isso, o gerente se concentra em "conversações" permanentes com uma extensa rede de interlocutores, de dentro e de fora da organização. Através das conversações, ele obtém uma informação "fresca" e "real" para a definição da agenda e pode negociar contatos. O POSD. CORB aparece novamente como um elemento secundário.(10) É necessário superar esse "gargalo", para se ter ge rentes eficientes, senão eles serão capazes apenas em relação às regras do jogo da administração, que pertence ao passado em termos de teoria gerencial.

Esses casos de questionamento, ilustram alguns modos de como pensar no tema. Eles têm suas raizes na realidade latino-americana, e chocam 


\section{ESTUDOS}

devido aos avanços da teoria gerencial e evidências empiricas sobre a realidade regional. Existem outros planos significativos, onde é possível detectar questionamentos em andamento.

\section{III - A NOVA FRONTEIRA TEC- NOLÓGICA}

Na segunda etapa da análise que propomos, queremos expor alguns desenvolvimentos que vão abrindo uma nova fronteira tecnológica. Alguns processos científico-técnicos em curso, no campo das disciplinas que estudam a administração pública a nivel particular, se constituem em direções inovadoras de trabalho com uma promessa significativa. Nossa apresentação será apenas exemplificadora e introdutória, de modo algum procurará esgotar a questão.

\section{A - DA GESTÃO "SIMPLISTA" À GESTÃO "COMPLEXA"}

Primeiramente, destacamos a orientação para a substituição de uma visão simplista da gestão, por uma visão complexa. O descobrimento da extrema complexidade da ação, no campo social e no organizacional, da sua dimensão e busca de instrumentos para manejar essa mesma complexidade, se apresenta, atualmente, com muito mais perguntas do que respostas. Alguns marcos de referência global sobre esse tema, talvez possam ser encontrados em trabalhos como os de Ilya Prigogine, Prêmio Nobel de Quimica em 1978, que estabeleceu as bases, dado que hoje se chama "ciência da instabilidade". A partir de suas experiências que detectam que, no campo das ciências naturais, existem fe-

\section{A irracionalidade como base para a ação e mudança organizacional}

nômenos instáveis e "misteriosos" para os quais deve-se criar outro paradigma, diferente daquele que se estava manejando, Ilya transporta alguns desses mecanismos de raciocínio ao campo das ciências sociais. Com uma equipe multidisciplinar, ele trabalha a idéia de que os sistemas sociais apresentam um equilíbrio instável, com fronteiras sumamente sensíveis, e por isso a irrupção de variáveis significativas produz ruptura do equilíbrio e dos circuitos aparentemente "enlouquecidos" de realimentação positiva. O básico não é trabalhar com suposto equilíbrio, más com discontinuidade, o estado normal é o das estruturas dissipativas. Tratar de compreender essa lógica do desequilibrio em lugar de acreditar numa racionalidade a priori, faz com que entremos no reino da alta complexidade. Isto tem tido conseqüências importantes nas organizações. Para ilustrar, lembraremos uma obra de NILS BRUNSSON que se intitula: "A irracionalidade como base para a ação e mudança organizacional".

O pesquisador questiona o difundido modelo da tomada racional de decisões, que procura otimizar as organizaçōes, orientando-se para objetivos satisfatórios. BRUNSSON diz que a aplicação estrita desse modelo leva à ineficiência organizacional, porque detecta-o como inibidor de comportamentos fundamentais, para que hajam decisões inovadoras. Aplicado, o modelo enfoca, especialmente, as áreas crescentes de incertezas, próprias ao contexto organizacional, e reage, afetando o compromisso, a motivação e as expectativas de ação e, finalmente, o inibe. Propõe a não aplicação do modelo na gerência concreta e a sua substituição por algo que chama "a ideologia organizacional" com grandes orientações que deverão retraduzir-se em cada tipo de situação específica. (1I) Aparece, aqui, a irracionalidade dentro do "sistema" questionando um ponto absolutamente básico como é o modelo de teoria das decisões, muito influente em alguns desenvolvimentos da ge rência moderan. Trata-se de captar desequilíbrios na mesma linha que, por exemplo, a pesquisa do governo municipal da Inglaterra, antes men- cionada, captava as coalizões cambiantes em relação a interesses múltiplos e fragmentados que são a vida organizacional concreta escapando dos pressupostos da racionalidade tradicional. Isto é muito mais complicado do que trabalhar com formalismo ou racionalidade pura, é passar do "simplismo" a, talvez, uma melhor aproximação da realidade e possibilidade de se obter maior eficiência na ação.

\section{B - A ORGANIZAÇÃO DO FUTURO}

Uma segunda linha de trabalho tem a ver com os cenários organizacionais projetáveis no futuro. $\mathrm{Na}$ área da gestão, o perfil do que se configura como a organização eficiente das próximas décadas, tende a incluir modelos e desenvolvimentos altamente diferentes dos tradicionais. Visualizase a passagem da organização hierárquica vertical para a multiforme. Trabalha-se em direção a modelos que permitem maximizar a flexibilidade organizacional. Face a esse contexto irracional e complexo, é fundamental que a organização seja capaz de reagir, de imediato, e produzir readaptações contínuas. Isso requer uma

\section{Visualiza-se a passagem da organização hierárquica vertical para a multiforme}

plasticidade interna, compativel com os modelos rígidos a que as propostas formalistas conduzem, como as do tipo Weberiano, tão difundido na administração pública. É necessário contar com a capacidade de agrupar e reagrupar forças permanentemente, frente a objetivos e programas em mudança rápida. Avançamos para uma organização onde o conceito matricial terá muita influência, onde as pessoas não vão fazer uma tarefa determinada durante muito tempo, mas vão participar de projetos que findarão dando lugar a outros. Aplicando o conceito de flexibilidade e os aportes da importante corrente do "enriquecimento do trabalho", surgirão matrizes onde existirão um rodizio de tarefas e configuraçōes orga- 


\section{ESTUDOS}

nizacionais muito distantes da divisão tradicional do trabalho. Caminha-se para organizações com a presença de equipes, e onde as decisões estratégicas não serão o produto de um "caudilho" organizacional mas a resposta a um trabalho de análise da situação que, necessariamente, será de equipe. Avançamos para organizações que vão promover o autoajustamento, que tem a ver com a descentralização, mas abrangendo muito mais.

Os principais membros da organização terão novos papéis. Dentro da nova situação, os supervisores, por exemplo, não supervisionarâo divisões mas estarão encarregados, fundamentalmente, de combinar ou coordenar as relaçôes entre as diferentes equipes auto-ajustadas. O nivel superior da organização trabalhará, especialmente, áreas tais como a vinculação estreita com o contexto, a lei= tura de seus sinais e a negociação interorganizacional em grande escala.

Essas e outras mudanças, de sentido igual, se tornam iminentes, através da procura de caminhos para alcançar eficiência frente a um contexto organizacional em transformaçì radical. Algumas das modificaçocs mencionadas não são para um futuro imediato, pois já foram incorporadas a algumas das organizalços publicas e privadas mais beml-stlcedidas a nivel internacional.

\section{C - VAIOR CENTRAL, IIA PAR- TICIPACÁ() ORGANIZACIO- NAI.}

A terceira linha de trabalho avançado, bem próxima da anterior, é que se refere à participação organizacional. Experiências controladas, realizadas sob diversas modalidades e em diferentes contextos, são concludentes em relação ao impacto sobre a melhoria da eficiência. Uma ampla pesquisa do Instituto Internacional de Relaçōes Trabalhistas da OIT, sobre os resultados práticos da participa- ção, identificam como vantagens concretas altamente significativas para a produtividade: a possibilidade do trabalhador sugerir idéias úteis, comunicações ascendentes muito valiosas para a direção; maior aceitação do trabalho pelos participantes; o trabalhador mais interessado em seu trabalho; os participantes podendo trabalhar de modo mais inteligente, se informados; e ainda a vantagem de poder atuar como incentivo à eficácia da direção.

\section{Uma ampla pesquisa sobre os resultados práticos da participação identificam como vantagens concretas, altamente significativas, para a produtividade}

A OIT ainda afirma, como conclusão, que: "A questão que se apresenta em nossos dias, não é de saber se deve ou não haver participação dos trabalhadores nas decisões da empresa, mas de como e com que formas essa participação vai se realizar".(12)

\section{D - DA REFORMA ADMINIS- TRATIVA Á REFORMA DO ESTADO}

Nas experiências mais inovadoras cm andamento, na região, realizando reforma em seu setor público, o discurso mudou e falamos, em vez de reforma administrativa, de reforma do Estado, expressão assim intitulada de modo pioneiro, pela atual Comissão Presidencial encarregada do assunto na Venezuela. Por detrás da mudança semântica estão, subjacentes, pro-

\begin{tabular}{c} 
Na nova fronteira, a \\
reforma se orienta para a \\
transformação do aparato \\
básico do Estado em seu \\
conjunto, democratizando-o \\
\hline
\end{tabular}

fundas mudanças conceituais. Na nova fronteira, a reforma não é a mera modificação dos aspectos puramente institucionais, ela se orienta para a iransformação do aparato politico básico do Estado em seu conjunto, democratizando-o.
Por outro lado, no discurso novo, a transformação sucedeu à modernização. Não se trata apenas de fazer ajustes técnicos modernizadores, isso é apenas uma das dimensões das mu danças que se procuram, e há muitas mais. Trata-se de transformar as correlações de poder, os jogos de interesse, as pautas culturais, as resistências à mudança, os niveis tecnológicos, os caudilhismos, etc.

A organização, como Colebatch e Deleging concluíram, é "uma prática social e modificá-la, é muito mais do que meros ajustes técnicos".

\section{E - A SUPERAC̃̃O) DA ANTI- NOMIA POLITIICOS X TÉC- NICOS}

A visão tradicional propunha, como condição "sine qua non", a eliminação das incidências políticas na gestão e na configuração de um corpo de burocratas puros no estilo Weberiano. As pesquisas indicam que, por detrás da persistência da politicagem na designação para os altos cargos, não existem apenas apetências clientelísticas. Trata-se, na América Latina e no Terceiro Mundo, de contar com uma burocracia realmente identificada com os grandes projetos de transformação nacional imprescindíveis para o progresso histórico.

A nova fronteira, na

América Latina, se orienta para a preparação de quadros de direção

Por outro lado, nos mesmos países desenvolvidos, existem providências significativas que estão sendo to madas para a politização dos altos cargos. ARNE LEEMANS assinala as prevenções a serem consideradas em relação ao avanço da burocracia sobre o poder político, e as tendências de uma repolitização de tais cargos em toda a Europa.(13)

Daniel Rowat identifica, nos países desenvolvidos, medidas concretas a serem tomadas em casos como do Canadá, onde uma Comissão Especial do Congresso, após ter investigado o tema, disse que uma boa parte 


\section{ESTUDOS}

do verdadeiro poder se encontrava nas mãos da alta burocracia. Entre essas medidas, acha-se a descentralização das decisões, um controle político maior sobre os serviços autônomos, a nomeação de um maior número de conselheiros políticos por parte dos altos níveis governamentais e, medidas para melhorar a representatividade social da alta burocracia, tratando de evitar que pertença exclusivamente às elites econômicas com as conseqüêntes tendenciosidades em sua atuação.(14)

A nova fronteira, na América Latina, se orienta para a superação da antinomia tradicional, através da preparação, e promoção, por diversas vias, de quadros de direção políticotécnicos que, ao mesmo tempo que garantem a identificação, com o fortalecimento da democracia e projetos nacionais básicos, tenham uma sólida formação técnica.

A orientação não é de formar um tecnocrata puro, mas chegar à combinação de um excelente técnico, com um funcionário ligado às realidades nacionais e com sensibilidade face aos dirigentes políticos e setores sociais maciços. Uma tal combinação não é fácil de ser gerada, mas parece ser um caminho muito mais promissor do que procurar "corpos de direção neutros" avaliativos perante os processos de mudança.

Nos países desenvolvidos, destacase a necessidade de contar com funcionários capazes de pôr em prática, por exemplo, os programas de ação afirmativa que procuram discriminar a favor de determinados setores da população como os preteridos, as minorias, as mulheres, etc. Em nosso caso, essas minorias costumam ser maiorias. Os discriminados e desfavorecidos representam, pelas características da crise social e econômica, amplos setores da população. $\mathbf{A}$ ação afirmativa é pois mais necessária do que nunca, e sugere a necessidade de se passar da antinomia simplista: po- líticos x técnicos, a uma apresentação mais complexa do problema.

Estas linhas de trabalho, vão mais ao encontro de uma orientação para gerar mais perguntas do que respostas, mas talvez revelem pistas reais para a obtenção de mudanças e de uma maior eficiência.

\section{A reforma deixou os} cenáculos tecnocráticos $e$ passou a fazer parte da grande agenda política

\section{IV - A REFORMA DA REFORMA}

A terceira e última etapa de reflexão que queremos desenvolver é introduzir como alguns processos inovadores de reforma do setor público estão sendo produzidos, baseando-se na superação dos "gargalos" conceituais e na abertura de novas linhas de fronteira tecnológica, e como essa experiência contribui decisivamente na elaboração de novos conhecimentos cientificos-tecnológicos.

Algumas idéias fundamentais sobre a "reforma reformada" serão apresentadas, sinteticamente, a seguir.

Primeiramente, a reforma deixou os cenáculos tecnocráticos e passou a fazer parte da grande agenda política. Países como a Argentina, o Uruguai, o Brasil, o Peru e a Venezuela, entre outros, estão hoje no centro do debate político nacional.

Segundo, a agenda da reforma que se está elaborando é muito cheia de novidades em relação à própria "administração pública convencional". Na América Latina, trabalha-se com temas tais como a participação do cidadão, transparência, controle social, o Estado criando condiçōes favoráveis à articulação e mobilização das potencialidades da sociedade civil, etc...

Em terceiro lugar, a estratégia reformista mudou decisivamente. Da etapa das reformas administrativas, onde todo tema era manipulado por uma elite que ia revelar a "verdade" da reforma do Estado a toda população, geralmente ao final do periodo presidencial e certamente com muito pouca utilidade, à variante não mais eficiente de tecnocratas muito mais sofisticados, aparentemente modernizadores mas elitistas e manipuladores, na medida em que não impulsionam processos conciliadores

\section{A estratégia reformista} mudou, está se passando às estratégias que enfatizam a conciliação social

mas tratam de digitar soluçōes sociais, está se passando a estratégias que enfatizam a conciliação social. Diz-se que não haverá reformas se não houver conciliação das forças políticas e sociais majoritárias; incluindo nessa conciliação os protagonistas diretos, os funcionários do Estado.

Existem, atualmente, modelos significativos, na América Latina, como por exemplo, a estratégia inovadora em andamento na Venezuela e orientada pela Comissão Presidencial para a Reforma do Estado, visando à celebração de amplos pactos políticos de longo prazo em relação aos temas centrais da reforma.

\section{As novas reformas estāo se processando a partir de equipes multidisciplinares, fazendo com que o nivel de criatividade aumente}

Em quarto lugar, a condução da reforma mudou de mãos totalmente, indo do monopólio dos juristas e administradores a âmbitos disciplinares mais vastos. As novas reformas estão se processando a partir de equipes multidisciplinares, onde se encontram políticos e especialistas pertencentes às diversas áreas das ciências sociais, além dos participantes anteriores fazendo com que o nível de criatividade aumente.

Existem processos significativos, a niveis particulares, das diferentes reato da reforma é a busca de laços efetivos entre o planejamento e a gestão pública.

Existem processos significativos a níveis particulares das diferentes realidades nacionais e um amplo proces- 


\section{ESTUDOS}

so regional impulsionado por entidades tais como OLPES e o CLAD apoiados pelo PNUD. Trata-se de articular uma visāo integrada em vez de trabalhar isolados pois senào estarão restringidas, severamente, às possibilidades de eficiência.

Um sexto ponto, em relação à reforma, enfatiza as potencialidades do trabalho, a nível de integração regional, em todos esses temas. Trata-se de, através de organismos como o IL.PES, no campo do planejamento, e o CLAD, no da gestão, trabalhar, cada vez mais, juntos e compartilhando fracassos e possibilidades. Essa orientaçào demonstrou que existe uma produtividade, em termos de otimização de recursos escassos, muito maior do que ficar copiando, em uníssomo, alguma receita de algum centro modernizador externo.

Desmitifica-se, com força

cada vez maior, a suposta ineficiência congênita do Estado

Um sétimo ponto dessa relaçio incompleta, apenas exploratória, i a desmitificação com força cada vez maior do que a suposta incficiencia congênita do Estado, mito essic implantado, propagandisticamentc, por setores interessados. Näo se esta discutindo se o Estado atual tem amplas áreas de incficiência ()u que uma reforma profunda é imprescindivel. Está se discutindo, isso sim, que a ineficiência do Estado é um "fato da natureza". Nào existem dados de pesquisas sérias, a nivel de comparaçào, que respaldem essa afírmativa que estaria baseada em claros fundamentos ideológicos, mas, existe, ao contrário, uma clara evidência empirica no sentido contrário. Assim, por exemplo, numa obra recente que analisa "a pesquisa sobre eficiência governamental" dois pesquisadores americanos, DOW'NS e LARKEY, assinalam que: "Os go- vernos são mais eficientes e as empresas privadas menos eficientes do que popularmente se acredita". Junto com a pesquisa comparada, eles expõem na obra uma série de casos de empresas privadas e públicas dos Estados Unidos que corroboram essa afirmação.(15) Na América Latina, assim mesmo, pode-se encontrar, em quase todos os países, organismos ou programas estatais que funcionaram, em niveis de excelência gerencial, por periodos prolongados, demonstrando que pode haver eficiência pública.

Na reforma da reforma está a conceituação de que a ineficiência é um fato inegável que precisa ser atacado, mas isso nada tem a ver com certa inferioridade congênita do setor público em relação ao setor privado, falácia questionável em todos os seus aspectos básicos.

\section{O sistema democrático é compativel com a eficiencia estatal}

Finalmente, a reforma da reforma está orientada por uma idéia-força diretora. Nius somente o sistema democritico ć compativel com a eficiência estatal, mas tambim, a única possibilidade real de alcançar ambas as metals estíl neste referencial de uniào. A democracia cria um marco de referência favorável às manifestações centrais da "organização" do futuro, como a participação, favorecendo, por conseguinte, a eficiência. O problema real, todavia, é de potencialização e de virtualização. Por outro lado, a essa altura dos acontecimentos históricos e da pesquisa existente, é possivel afirmar, com forte sustentaçào, que autocracia sim é que é equivalente à ineficiência. $\mathrm{O}$ caso das experiências recentes no Cone Sul ilustraram esse fato de modo categórico. Cada um dos elementos do que seria um modelo gerencial moderno, orientado para alcançar eficiência, é incompativel com aspectos fundamentais do modelo autocrático.

O desafio e a grande promessa está na conjunção da democracia com a eficiência. A questão é saber se a comunidade científico-técnico-profissional, que trabalha ao redor do tema, será capaz de caminhar nessa direção.

\section{BIBL IOGRAFIA}

1. SELF Peter. What's gone wrong with Public Administration and Development.

Royal Instutue of Public Administration, October - December, 1986.

2. NIETO Alejandro. Los estudios sobre la administración pública.

3. RAM Rati. - Government size and economic growth: a new framework and some evidence from cross-section and time-series data. The American Economic Review, March, 1986.

4. O autor tratou o tema detalhadamente em B. Kliksberg, "El pensamiento organizativo: del Taylorismo a la teoria de la organizacion".

5. COLEBATCH H.K. e DEGELING P. Talking and doing in the work of administration.

Public Administration and Development. Royal Institute of Public Administration, October - December, 1986.

6. KELLY Rita Mae. An introduction and overview. Symposium: Productivity, Societal Well-Being, and Public Policy. Policy Studies Review. Arizona State University, February, 1985.

7. KENNEDY John F.School of Government, Harvard University 1987-88.

8. L' Institut de Management Public. CESMAP. Paris, 1984

9.MINTZBERG Henry. La alta dirección: mitos y realidades. Harvard $\mathrm{Bu}$ siness Review. July-August, 1975.

10. KOTTER John P. What effective general managers really do? Havard Business Review, November - December, 1982. Kotter assinala: "Existe uma brecha bastante grande entre o saber convencional sobre ferramentas e funções gerenciais de um lado, e o comportamento gerencial, do outro".

11. BRUNSSON Nils. The Irrational Organization: Irrationality as a Basis for Organizatinal Action and Change. Wiley, N. Y., 1985.

12. OIT - Participación de los trabajadores en las decisiones de la empresa. Ginebra, 1981.

13. LEEMANS Arne F. La carrière dans la Fonction Publique: évolution récente dans les pays europeens. Revue Internationale des Sciences Administratives. Volume 53, 1987, N. 1.

14. ROWAT Donald C. Bureaucracy and Policy-making in developed democracies: the decline of bureaucratic inMuence. Revista Internacional de Ciências Administrativas. Volume L1, 1985, N. 3

15. DOW NS Gerorge W. and LARREY Patrick D. The Search for government efficiency. New York, Random House, 1986. 